\title{
Life-Threatening Infections Due to Live-Attenuated Vaccines: Early Manifestations of Inborn Errors of Immunity
}

\author{
Laura Pöyhönen $^{1}$ - Jacinta Bustamante ${ }^{1,2,3,4}$. Jean-Laurent Casanova ${ }^{1,2,3,5,6} \cdot$ Emmanuelle Jouanguy ${ }^{1,2,3}$. \\ Qian Zhang ${ }^{1}$
}

Received: 26 February 2019 / Accepted: 2 May 2019 / Published online: 23 May 2019

(C) Springer Science+Business Media, LLC, part of Springer Nature 2019

\begin{abstract}
Live-attenuated vaccines (LAVs) can protect humans against 12 viral and three bacterial diseases. By definition, any clinical infection caused by a LAV that is sufficiently severe to require medical intervention attests to an inherited or acquired immunodeficiency that must be diagnosed or identified. Self-healing infections can also result from milder forms of immunodeficiency. We review here the inherited forms of immunodeficiency underlying severe infections of LAVs. Inborn errors of immunity (IEIs) underlying bacille Calmette-Guérin (BCG), oral poliovirus (OPV), vaccine measles virus (vMeV), and oral rotavirus vaccine (ORV) disease have been described from 1951, 1963, 1966, and 2009 onward, respectively. For each of these four LAVs, the underlying IEIs show immunological homogeneity despite genetic heterogeneity. Specifically, BCG disease is due to inborn errors of IFN- $\gamma$ immunity, OPV disease to inborn errors of B cell immunity, $v \mathrm{MeV}$ disease to inborn errors of IFN- $\alpha / \beta$ and IFN- $\lambda$ immunity, and ORV disease to adaptive immunity. Severe reactions to the other 11 LAVs have been described yet remain "idiopathic," in the absence of known underlying inherited or acquired immunodeficiencies, and are warranted to be the focus of research efforts. The study of IEIs underlying life-threatening LAV infections is clinically important for the affected patients and their families, as well as immunologically, for the study of the molecular and cellular basis of host defense against both attenuated and parental pathogens.
\end{abstract}

Keywords Live-attenuated vaccine $\cdot$ primary immunodeficiency $\cdot$ inborn error of immunity $\cdot \mathrm{BCG} \cdot \mathrm{OPV} \cdot \mathrm{MMR} \cdot \mathrm{ORV} \cdot \mathrm{IFN}$

\section{Introduction}

Vaccines have been extraordinarily successful in the fight against human infectious diseases since the end of the

Laura Pöyhönen and Jacinta Bustamante contributed equally to this work.

Qian Zhang

qzhang02@mail.rockefeller.edu

1 St. Giles Laboratory of Human Genetics of Infectious Diseases, Rockefeller Branch, The Rockefeller University, New York, NY, USA

2 Laboratory of Human Genetics of Infectious Diseases, Necker Branch, INSERM U1163, Paris, France

3 Imagine Institute, Paris Descartes University, Paris, France

4 Center for the Study of Primary Immunodeficiencies, AP-HP, Necker Hospital for Sick Children, Paris, France

5 Pediatric Hematology-Immunology Unit, Necker Hospital for Sick Children, Paris, France

6 Howard Hughes Medical Institute, New York, NY, USA nineteenth century [1-4]. The first vaccines were liveattenuated vaccines (LAVs), obtained by the attenuation of virulent infectious agents [5]. Louis Pasteur formulated the idea of attenuation, performed the famous anthrax challenge experiment in cattle at Pouilly-le-Fort in 1881, and coined the term "vaccination" as a tribute to Edward Jenner [5]. Chemically inactivated and genetically engineered vaccines have been developed since 1896 [5], and up to 15 LAVs have been used since then. The smallpox (1798) and rabies (1885) vaccines are no longer used. The bacille Calmette-Guérin (BCG) vaccine against tuberculosis (TB) was developed through serial cultures of Mycobacterium bovis by Albert Calmette and Camille Guérin in 1927 [5, 6]. The yellow fever (YF) vaccine strain 17D was obtained by Max Theiler in 1935, through serial passages of the wild-type Asibi strain in tissue culture [7-10]. The discovery that cultured cells in vitro could be used as substrates for viral growth revolutionized vaccine development. The oral poliovirus vaccine (OPV) was developed through serial passaging in cell culture, by Albert Sabin, in 1961 [11, 12]. Similar techniques were used for the development of the measles, mumps, and rubella virus 
vaccines in 1963, 1967, and 1969, respectively [13-15]. These three LAVs were subsequently combined into a single vaccine, MMR, which has been available since 1971 and is sometimes administered together with the varicella virus vaccine (MMRV). Since the 1980s, other LAVs have been developed with similar approaches. These LAVs include the adenovirus (1980), typhoid (1989), varicella (1995), rotavirus (1999 and 2006), cholera (1994), influenza (1999), and zoster (2006) vaccines [5]. Some of these LAVs are gradually being replaced by chemically inactivated and/or genetically engineered alternatives.

LAVs act by causing self-limited infections with weakly virulent vaccine pathogens, thereby establishing a longterm immunological memory against specific antigens common to the more virulent parental pathogen. However, LAV infections are not self-limited in all individuals. In rare cases, LAVs can cause life-threatening infections that are fatal or could be fatal without modern medical intervention. LAV infections contrast with naturally occurring infections in that they provide us with a unique opportunity to study host defense in humans under almost experimental conditions, because the similar inoculum of a well-defined, homogenous pathogen is inoculated, via the same route, to thousands or millions of individuals. In this setting, the rare cases of clinically severe LAV infections observed attest to the inevitable inter-individual variability of human populations. Indeed, after the first mass campaigns of vaccination with $\mathrm{BCG}, \mathrm{OPV}, \mathrm{vMeV}$, and oral rotavirus vaccine (ORV), rare, but severe infections caused by these supposedly benign microbes were reported, the first cases being noted in 1951, 1963, 1966, and 2009, respectively [16-20]. Studies of inborn errors of immunity (IEIs), previously known as primary immunodeficiency diseases (PIDs), advanced rapidly in the 1950s and 1960s. As a result, severe LAV infections were recognized in patients with well-defined IEIs: BCG in severe combined immunodeficiency or combined immunodeficiency (SCID or CID) in 1957 [21, 22], OPV in agammaglobulinemia in 1963 [23-25], vMeV in SCID in 1971 [26], and ORV in SCID in 2009 [19, 20]. The description of these severe infections, together with the discovery of increasing numbers of overt immunodeficiencies, contributed to the traditional concept that immunodeficient patients are susceptible to various "weakened" or "opportunistic" infections. However, recent findings have clearly demonstrated that some IEIs underlie a specific predisposition to certain LAVs (Table 1), as illustrated by Mendelian susceptibility to mycobacterial disease (MSMD) in patients with defective type II IFN (IFN- $\gamma$ ) immunity [27, 28] and fatal measles vaccine infection in patients with defective type I and III IFN (IFN- $\alpha / \beta$ and IFN- $\lambda$ ) immunity [29-31, 218]. Vaccination is often performed in very young children, including infants. LAV infections can, therefore, be the first and most severe infections of patients with IEIs (Table 1). We will not deal here with the 11 LAVs for which infections remain "idiopathic" [3,5].

Table 1 LAV infections in patients with inborn errors of immunity

\begin{tabular}{|c|c|c|c|c|c|}
\hline \multicolumn{2}{|c|}{ Live-attenuated vaccine } & $\mathrm{BCG}$ & ORV & OPV & $\mathrm{vMeV}$ \\
\hline \multicolumn{2}{|c|}{ Age at vaccination } & After birth & 2 months, 4 months, & 2 months, 4 months, & $12-15$ months, $4-6$ years \\
\hline \multirow[t]{4}{*}{ Syndromic } & Humoral & & & XLA, CVID & \\
\hline & $\begin{array}{r}\text { Cellular and } \\
\text { combined }\end{array}$ & SCID, CID & SCID & SCID, CID & $\begin{array}{l}\text { SCID, CID, idiopathic } \\
\mathrm{CD} 4^{+} / \mathrm{CD}^{+} \mathrm{T} \\
\text { lymphopenia }\end{array}$ \\
\hline & $\begin{array}{l}\text { NADPH } \\
\text { oxidase } \\
\text { activity }\end{array}$ & $\begin{array}{l}\text { XR-gp91 } 1^{\text {phox }}, \text { AR-p } 47^{\text {phox }}, \text { AR-p } 67^{\text {phox }} \\
\text { AR-p40 } \\
\text { phox } \\
\text { AR-p22 }\end{array}$ & & & \\
\hline & $\begin{array}{l}\text { Innate and } \\
\text { intrinsic }\end{array}$ & $\begin{array}{l}\text { AR-JAK1, AR-RORC, AR-TYK2, } \\
\text { AR-STAT1, AR-IRF8, XR-NEMO, } \\
\text { AR-ISG15 }\end{array}$ & & & $\begin{array}{l}\text { AR-STAT1, AR-STAT2, } \\
\text { AR-IRF7, AR-IRF9 }\end{array}$ \\
\hline Isolated & $\begin{array}{l}\text { Innate and } \\
\text { intrinsic }\end{array}$ & $\begin{array}{l}\text { AR/AD-IFN- } \gamma \text { R1, AR/AD-IFN- } \gamma \text { R2, } \\
\text { AR-IL-12p40, AR-IL-12R } \beta 1, \\
\text { AR-IL-12R } \beta 2, \text { AR-IL-23R, } \\
\text { AD-STAT1, } \\
\text { AD-IRF8, AR-TYK2 (P1104A), } \\
\text { AR-SPPL2A, XR-NEMO (E315A, } \\
\text { R319Q), XR-gp91 }{ }^{\text {phox }} \text { (Q231P, T178P) }\end{array}$ & & & $\begin{array}{l}\text { AR-IFN- } \alpha \text { R2, } \\
\text { AR-IFN- } \alpha \text { R1 }\end{array}$ \\
\hline
\end{tabular}

Genetic defects of patients with IEIs conferring susceptibility to BCG, OPV, ORV, or vMeV. IEIs are assigned to categories according to the type of immunity affected 


\section{Life-Threatening Infections Caused by BCG}

\section{Mycobacterium and BCG}

The BCG vaccine was developed in France by Albert Calmette and Camille Guérin. It is administered to 120 million newborns annually in developing countries, where tuberculosis remains a major health problem [32-34]. The vaccine provides protection principally against miliary tuberculosis and meningitis in infants. It consists of a live-attenuated strain of Mycobacterium bovis that induces an immune response providing protection against the more virulent Mycobacterium tuberculosis. The BCG vaccine is considered to be safe in the general population, but complications have arisen following the vaccination of infants with IEIs [33, 35, 36]. Localized BCG infections (BCG-itis) are observed in about 1 in 2500 vaccinated individuals, and disseminated infections (BCG-osis) occur in about 1 in 50,000 vaccinated individuals, excluding HIV-infected individuals [33, 37-39]. Disseminated BCG infection should be seen as evidence for an acquired or primary immunodeficiency and is associated with a high mortality rate $[16,35,40]$. The clinical signs leading to a suspicion of BCG infection are usually straightforward: a local abscess or severe ulcer at the injection site, or involvement of the regional ipsilateral ganglia with suppuration, fistula formation, or both, is observed shortly after vaccination [41]; in BCG-osis, distal lymph nodes, skin, lungs, bone, liver, spleen, and the central nervous system (CNS) are involved [42]. However, microbiological evidence is not always available, and diagnosis is often based solely on clinical findings. Acquired immunodeficiency, due to HIV infection, may underlie rare cases of BCG-osis [43]. BCG disease in the context of MSMD has recently been reviewed [28, 44, 45]. We will focus here on the various inherited forms of BCG disease.

\section{Severe and Combined Immunodeficiencies}

SCID is a heterogeneous group of rare IEIs characterized by the absence of $\mathrm{T}$ cells, and in some cases of B and/or NK cells, resulting in defects of both cellular and humoral immunity [42, 46, 47]. Infants with SCID are, therefore, at high risk of developing life-threatening infections if they are inadvertently given LAVs, such as BCG, OPV, MMR, or ORV (Table 1) [48]. Despite their overt immunodeficiency, infants with SCID frequently remain undiagnosed until they suffer from vaccine-associated infections, particularly in the absence of a family history [49]. BCGassociated infections in SCID patients present as fever, ulcer, or abscess at the vaccination site, pneumonia, hepatosplenomegaly, osteomyelitis, hepatic abscess, inguinal abscess, and meningoencephalitis [50-52]. One study of a large cohort of 349 BCG-vaccinated SCID patients from 17 countries showed that $51 \%$ developed BCGassociated infections. Surprisingly, children vaccinated after the age of 1 month developed fewer BCG-associated infections $(37.9 \%)$ than children vaccinated earlier $(55.4 \%$ BCG-associated infection and $18 \%$ BCG-associated mortality) and suffered almost no BCG-associated mortality, although the mechanisms underlying this difference remain unclear [37]. Some patients with CID, such as purine nucleoside phosphorylase (PNP) deficiency, also develop BCG-osis, although the clinical and immunological phenotypes of these patients are milder than those of SCID patients (Table 1) [53, 54].

\section{Chronic Granulomatous Disease}

Chronic granulomatous disease (CGD) is an IEI that affects 1 in 250,000 newborns [55, 56]. CGD patients are highly susceptible to multiple life-threatening bacterial (including mycobacteria) and fungal infections, and, less commonly, parasitic infections [57]. This disease is defined by the total absence or low levels of reactive oxygen species (ROS) due to defects of the nicotinamide adenine dinucleotide phosphate (NADPH) oxidase complex in phagocytes, including neutrophils, monocytes, macrophages, and dendritic cells, and in B lymphocytes [28, $45,58-60]$. The most common defect is caused by monoallelic mutations of the $\mathrm{X}$-linked recessive (XR) $C Y B B$ gene encoding the gp9 $1^{\text {phox }}$ subunit of the NADPH oxidase complex $[61,62]$. Less common defects include biallelic mutations of the NCF1, NCF2, NCF4, CYBA, and $C Y B C 1$ genes encoding the $447^{\text {phox }}, \mathrm{p} 67^{\text {phox }}, \mathrm{p} 40^{\text {phox }}$, $\mathrm{p} 22^{\text {phox }}$, and EROS proteins, respectively [55, 63, 64]. These defects result in the patients' phagocytes being unable to produce sufficient ROS, enabling BCG and other pathogens to survive within cells $[28,45]$. CGD was one of the first diseases found to underlie BCG infections, and increasing numbers of $\mathrm{BCG}$ infections are being reported in CGD patients [16, 33, 60, 65-71]. BCG vaccination is often mandatory or recommended in regions in which the TB burden is high, resulting in more CGD patients suffering from BCG infection than $\mathrm{TB}$ in these regions. One study showed that as many as $75 \%$ of CGD patients presented with BCG infection, with $18 \%$ BCG-associated mortality [60]. Moreover, because of early vaccination, $\mathrm{BCG}$ infection is the first clinical manifestation in $60 \%$ of CGD patients, often presenting as lymphadenitis ipsilateral to the vaccination site $[60,71,72]$. The vast majority of mutations affecting the NADPH oxidase complex result in equally low levels of ROS production in all phagocytes. Rarely, specific $C Y B B$ mutations result in defects preferentially affecting certain cell types $[60,73]$, as discussed in the next section. 


\section{Mendelian Susceptibility to Mycobacterial Disease}

Mendelian susceptibility to mycobacterial disease (MSMD) is a group of inborn errors that predisposes patients to infections with both less virulent mycobacteria (BCG and environmental mycobacteria (EM)) and more virulent $M$. $t b$. The severity of BCG infections in MSMD patients ranges from localized infections to disseminated and life-threatening infections. Mycobacterial infections generally begin during childhood in MSMD patients, but they may emerge during adolescence or even adulthood in some patients, and BCG infections are often, but not always, the first sign of the disease (Table 1). MSMD patients display considerable genetic heterogeneity. Defects of 12 genes (IFNGR1, IFNGR2, IL12B, IL12RB1, IL12RB2, IL23R, STAT1, IRF8, TYK2, SPPL2A, specific $N E M O$, and $C Y B B$ ) have been identified in patients with isolated MSMD (Table 1). Patients with isolated MSMD display no overt abnormalities in routine hematological or immunological tests [28, 45]. Certain alleles at some loci underlie isolated MSMD, whereas others underlie syndromic MSMD, in which mycobacterial diseases occur in combination with other phenotypes. Defects of six genes (JAKl, RORC, ISG15, STAT1, IRF8, and specific TYK2) are often, but not always, associated with syndromic MSMD [28, 45, $74,75]$. Despite this genetic heterogeneity, all the mutations identified to date lead to deficiencies of type II interferon (IFN- $\gamma$ )-mediated immunity, controlling the production of, or response to IFN- $\gamma$, or both (Fig. 1) [27, 28, 45, 76, 77]. Two gene defects have only recently been identified [78], but the other genetic etiologies of MSMD were recently reviewed $[28,44,45]$. In addition to locus heterogeneity, there is allelic heterogeneity, as different defects (recessive vs. dominant; complete vs. partial; loss of expression vs. loss of function) of the same gene can underlie different disorders. Furthermore, incomplete penetrance is common in MSMD, which is Mendelian only for the most severe forms, adding another layer of complexity to the disease [79].
The identification of genetic etiologies that can cause isolated and/or syndromic MSMD, together with CGD and SCID/CID, suggests that host defense against BCG is dependent on the IL12/23/ISG15-IFN- $\gamma$ signaling circuits formed between IL-12-, IL-23-, and ISG15-producing phagocytes and IFN- $\gamma$-producing leukocytes (Fig. 1). Autosomal recessive (AR) complete IFN- $\gamma \mathrm{R} 1$ and IFN- $\gamma \mathrm{R} 2$ deficiencies are the most severe forms of MSMD. Affected patients suffer from disseminated infections of BCG and/or EM, and occasionally TB, without structured granulomas $[28,45]$. AR partial IFN- $\gamma \mathrm{R} 1$ and IFN- $\gamma \mathrm{R} 2$ deficiencies are less severe, except for the IFN- $\gamma$ R 1 p.M1T and IFN- $\gamma$ R2 p.M1V mutations, which present cell-specific residual expression and are as clinically severe as complete deficiency [80, 81]. Monoallelic IFNGR1 mutations underlie autosomal dominant (AD) partial deficiency $[82,83]$. Affected patients develop multiple mycobacterial osteomyelitis (caused by BCG in particular) $[28,45$, 84]. Unlike IFN- $\gamma$, which is homodimeric, both IL-12 and IL23 are heterodimers, each containing the IL-12p40 subunit encoded by $I L 12 B$. Similarly, the receptors of IL-12 and IL23 have a subunit in common: IL-12R $\beta 1$, encoded by IL12RB1 (Fig. 1). Patients with IL-12p40 or IL-12R $\beta 1$ deficiency have defects of both IL-12 and IL-23 signaling and are susceptible to mycobacterial disease, Salmonella infections, and chronic mucocutaneous candidiasis (CMC) [28, 45]. Defects of the unique subunit of IL-12 (IL-12R $\beta 2$, encoded by $I L 12 R B 2$ ) or of the IL-23 receptor (IL-23R, encoded by $I L 23 R$ ) are much rarer, but also underlie MSMD [78]. IL$12 \mathrm{R} \beta 2$ and IL-23R are often expressed on different cell types, and this results in $\alpha \beta \mathrm{T}, \gamma \delta \mathrm{T}, \mathrm{B}, \mathrm{NK}$, ILC1, and ILC2 cells preferentially producing IFN- $\gamma$ in response to IL-12, whereas NKT and MAIT cells preferentially produce this cytokine in response to IL-23. This compensation mechanism results in IL-12R $\beta 2$ and IL-23R deficiencies having a much lower clinical penetrance than IL-12R $\beta 1$ deficiency $[78,79]$. Indeed, IL-12R $\beta 1$ deficiency is the most frequently reported etiology of MSMD [28, 45, 85].
Fig. 1 Schematic representation of type II IFN-related genetic disorders associated with BCG infections. In red, genes for which mutations have been associated with BCG infections. In black and white, genes not associated with BCG infections

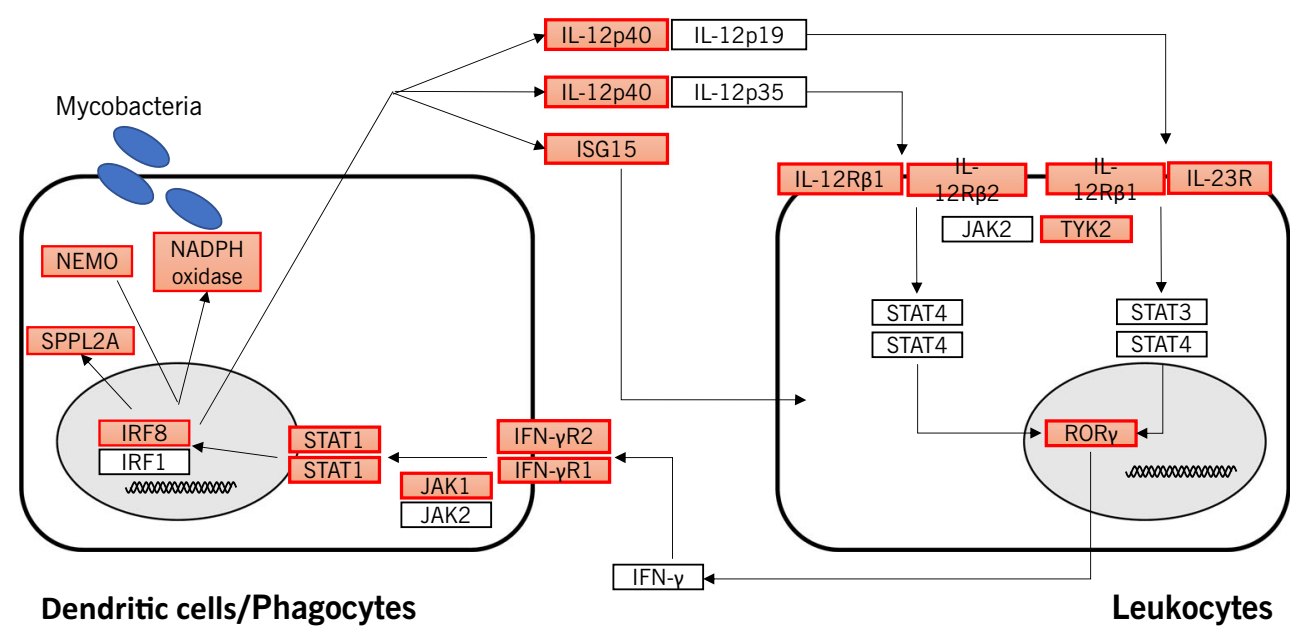


Mutations at six MSMD-causing loci, JAK1, STAT1, IRF8, SPPL2A, NEMO, and CYBB, primarily impair phagocyte function in host defense against mycobacterial infections $[28,45]$. JAK1, one of the four Janus kinases (JAKs), binds the IFN- $\gamma$ receptor to induce the phosphorylation and homodimerization of STAT1 upon IFN- $\gamma$ stimulation. Defects of JAK1 or STAT1 therefore block responses to IFN- $\gamma$ in phagocytes. Patients with AD partial STAT1 deficiency can present with isolated MSMD, whereas patients with AR STAT1 deficiency are also susceptible to viral and pyogenic infections $[44,45]$. Both IRF8 and SPPL2A are essential for the development and survival of IL12/23producing phagocytes. AR IRF8 deficiency leads to a complete absence of circulating monocytes and dendritic cells (DCs) and causes syndromic MSMD, whereas AD IRF8 deficiency leads to a selective depletion of circulating

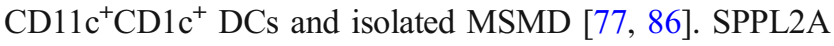
deficiency leads to the accumulation of undegraded HLA fragments in HLA class $\mathrm{II}^{+}$myeloid and lymphoid cells. Patients display a selective depletion of $\mathrm{CD} 1 \mathrm{c}^{+} \mathrm{DCs}$ and their progenitors [77]. The Q231P and T178P mutations of CYBB, which lead to selective impairment of the NADPH oxidase activity in monocyte-derived macrophages, cause isolated MSMD [74]. The E315A and R319Q mutations of NEMO impair the CD40-CD40L signaling-dependent production of IL-12 (Fig. 1) and cause isolated MSMD [87]. On the other side of the circuit, defects of TYK2 and RORC are found to primarily impair lymphocyte function in host defense against BCG $[76,88]$. TYK2 belongs to JAK protein family and binds the IL-12 and IL-23 receptors to induce the phosphorylation and dimerization of STAT3 and STAT4. TYK2 defects lead to both isolated and syndromic MSMD [76, 89]. Homozygosity for the P1104A allele of TYK2, which selectively disrupts IL23 responses, is a rare genetic etiology of MSMD [89]. Defects of RORC result in impaired IFN- $\gamma$ production by $\gamma \delta \mathrm{T}$ cells and $\mathrm{CD} 4^{+} \mathrm{CCR} 6^{+} \mathrm{CXCR} 3^{+} \alpha \beta \mathrm{T}$ cells and a lack of IL-17-producing cells. Affected patients therefore suffer from both MSMD and CMC [88].

\section{Next-Generation Vaccines Based on BCG and Their Potential Impact on IEI Patients}

Although BCG has been in use for almost 100 years worldwide, its low efficacy, especially poor protection against pulmonary TB, has encouraged great effort to the development of alternatives based on the original BCG [90, 91]. We will not discuss the strategies introduced to increase the efficacy here, but rather focus on the safety of these new vaccines in IEI patients. At least seven strategies have been explored for decreasing the virulence of the vaccine. Deletion of the mbtB protein disrupts the synthesis of siderophore mycobactin and limits the replication of the strain in vivo [92]. Engineered expression of the Listeria monocytogenes protein listeriolysin
O (LLO) instead of urease C leads to perturbation of phagosome following macrophage phagocytosis and leakage of bacterial DNA into the cytosol to trigger type I IFN response [93]. Other strategies with similar mechanisms include insertion of esx 1 to enhance the function of ESX-1 secretion system [94] and expression of the cholesterol-binding cytoslysin perfringolysin $\mathrm{O}$ (Pfo), a pore-forming protein normally secreted by Clostrididium perfringens [95]. In contrast, depletion of zmp1, a putative $\mathrm{Zn}^{2+}$ metalloprotease, increases the activation of inflammasome and the maturation of phagosomes [90]. Deletion of $\mathrm{pdx} 1$, a pyridoxine synthase, makes it auxotrophic for vitamin $\mathrm{B}_{6}$ in a concentrationdependent manner [96]. Deletion of nuoG gene, which encodes type I NADH dehydrogenase complex that inhibits ROS production, leads to more macrophage apoptosis [97]. All of these strategies were shown to be safer than original BCG in SCID mice therefore might be beneficial to SCID/CID patients [90]. However, it remains unclear whether the strategies involving rupture of phagosome or maturation of macrophage are safer for CGD patients. A different set of strategies aims to enhance the immune responses by co-expressing human cytokines, including single or a combination of IFN- $\gamma$, IL-12, IL-18, IL-4, IL-6, GM-CSF, IL-15, and TNF- $\alpha$ [90]. It will be important to determine whether co-expression of IFN- $\gamma$ is safer for MSMD patients than original BCG.

\section{Life-Threatening Infections Caused by the OPV}

\section{Polio and the OPV}

Poliomyelitis is a severe infectious disease caused by poliovirus, a positive-stranded human RNA enterovirus. Poliomyelitis began to cause regular epidemics at the end of the nineteenth century [1]. This disease mostly affects infants and children. Poliovirus (known as the poliomyelitis virus at the time) was first identified in 1908 [98]. There are three serotypes of poliovirus, and infection with any one of these serotypes does not provide cross-protection against the other serotypes. Poliovirus causes an acute, self-limited infection in most people, first described by Albert Sabin and others in the 1940s [99-101]. The virus is ingested via the fecal-oral or oral-oral route. It then replicates in the pharynx and gastrointestinal tract and can be isolated from multiple sites, including the tonsils, Peyer's patches, and the mesenteric lymph nodes of the intestine [101]. Infected individuals shed the virus in pharyngeal secretions and feces over a period of 2 to 8 weeks. Almost $95 \%$ of infected individuals develop no symptoms [102], and only a very small proportion $(0.1$ to $1 \%)$ of infected individuals develop paralytic disease [103]. Fatalities are observed in $2-5 \%$ of children and $15-30 \%$ of adults displaying paralytic disease [102]. The rarity of fatal infections suggests 
that severe poliovirus infections may be caused by IEIs. The OPV (or live) was developed by Albert Sabin and has been widely used over the last 50 years [104]. Being an oral vaccine, the OPV has the advantages of being easy to administer and highly effective [105]. Together with inactivated poliovirus vaccine (IPV), OPV has decreased the global incidence of poliomyelitis by $99.9 \%[106,107]$. This considerable success of vaccination campaigns has resulted in the near eradication of poliovirus infections, with only 22 cases of poliomyelitis reported in 2017, in only two countries [108].

Unlike the earlier LAVs (BCG and YF vaccine), OPV was attenuated in cell culture rather than in live animals, thanks to methods developed in the 1940s for the culture of many viruses, including poliovirus and measles virus, in vitro [5]. Successive passages in different cell cultures in vitro yielded variants of the three poliovirus serotypes (Sabin 1, 2, and 3) devoid of neurovirulence, but capable of replicating in the gastrointestinal tract $[1,105]$. However, OPV protects vaccinated individuals against viremia, but not against infection with the same OPV, as shown by the shedding of smaller amounts of virus over a shorter period in children receiving a second dose of OPV. OPV induces specific long-lasting immunity in recipients by establishing a self-limited infection resembling that caused by virulent poliovirus. In normal individuals, the vaccine strains replicate in the pharynx and intestine for 2 to 8 weeks, inducing humoral and mucosal immunity $[106,109]$. However, in a small number of vaccinated individuals, OPV may mutate and evolve into vaccinederived poliovirus (VDPV) during replication [110]. VDPV can reacquire neurovirulence, leading to outbreaks of disease in regions with low levels of OPV coverage [110]. Since 2000, VDPV outbreaks have occurred in 18 countries. Most of the reported cases $(87 \%)$ were associated with type 2 viruses, the wild-type counterpart of which has been eradicated worldwide [110]. Thus, VDPV has replaced the wild-type virus as a major threat to global heath. Prompted by these major changes in polio epidemiology, OPV has been gradually replaced with bivalent (types 1 and 3 ) or inactivated vaccines over the last 5 years [107, 110-112].

In rare cases, OPV can cause vaccine-associated paralytic poliomyelitis (VAPP), which is characterized by acute flaccid paralysis and residual paralysis $[104,105,110,113,114]$. The incidence of VAPP is $1-1.3$ cases per million births, suggesting that the individuals affected probably have IEIs. VAPP can develop in children or adults, but adult cases are rare nowadays, due to the high levels of vaccination coverage, beginning at the age of 2 months (Table 1) [115, 116]. However, the occurrence of VAPP in adults indicates that some patients may be specifically susceptible to OPV but resistant to many other infections and otherwise healthy. Moreover, the high vaccination coverage during infancy has resulted in a situation in which almost all patients with IEIs are vaccinated with OPV before the appearance of their phenotypes. However, the incidence of VAPP is as low as 1/7000, even among patients with well-defined IEIs [106, 114, 117-121]. Patients with well-defined IEIs, with or without VAPP, have also been reported to excrete the virus in the long term $[106,114$, 117-121]. Since the introduction of OPV, virus excretion has been reported in more than a hundred patients with various IEIs worldwide [106], and most of these cases were detected after the onset of VAPP [122]. The excreted viruses often diverge considerably $(>0.6-1 \%$ nucleotide sequence divergence) from the original OPV strain $[11,114]$. These longterm excretors have thus become a major reservoir of VDPV.

\section{Severe and Combined Immunodeficiencies}

SCID and CID patients are prone to enteroviral infections and VAPP. A third of the 107 VAPP cases reviewed recently had SCID (36 patients) or CID (2 patients) [106]. Patients with MHC2, ARTEMIS, and RAG1 or 2 deficiencies were reported, but genetic diagnoses were not available for all patients $[46,48,52,106,114]$. Moreover, the observed penetrance of VAPP is incomplete. For instance, only a few MHC2-deficient patients have developed manifestations of paralysis, even though MHC2 deficiency is an AR form of CID characterized by the impaired development of $\mathrm{CD} 4^{+} \mathrm{T}$ cells and antigenspecific antibody production by B cells [123-125]. SCID patients had the lowest probabilities of clearing the virus before death or last documented follow-up. Several other studies have reported CID patients to be susceptible to asymptomatic enteroviral infections [126-128]. All the patients mentioned here have defects of cellular and humoral immunity (due to B cell intrinsic or extrinsic disorders). There have been no consistent reports of patients with acquired immune deficiency (AIDS) developing persistent poliovirus excretion, suggesting that the clearance of this virus is mediated principally by antibodies $[129,130]$.

\section{Hypo/Agammaglobulinemia Due to B Cell-Intrinsic Disorders}

$\mathrm{X}$-linked agammaglobulinemia (XLA) is a IEI caused by defects of Bruton's tyrosine kinase (BTK) gene. These defects block the pro-B to pre-B stage of differentiation in the bone marrow, resulting in the almost total absence $(<1 \%)$ of circulating B lymphocytes and very low levels of antibody production [131]. Patients present bacterial infections and are highly susceptible to enterovirus infections, including chronic meningoencephalitis, severe dermatomyositis, and VAPP [131]. XLA patients were found to be particularly susceptible to VAPP after OPV use became widespread [110, 132], and many cases have since been reported [106, 133]. However, only a small proportion of XLA patients develop severe or chronic OPV infections, despite having a much higher relative risk than the general population. An estimated 7\% of XLA 
patients develop prolonged excretion [119], and $0.6-3 \%$ of XLA patients given three doses of OPV developed VAPP $[134,135]$, whereas the other excretors remained asymptomatic. However, mortality rates can be as high as $62 \%$ when these patients present VAPP [136]. Intravenous or subcutaneous IgG replacement therapy effectively decreases the incidence of bacterial infections in XLA, but not prolonged excretion [131]. In some long-term excretors with XLA, IgG replacement therapy failed to clear the virus from the intestine [137]. The high susceptibility of XLA patients to VAPP suggests that humoral immunity is indispensable in host defense against poliovirus, particularly against the neurological spread of the virus. Surprisingly, virus shedding ended spontaneously in some XLA patients, suggesting a role for immune functions other than antibody responses in the control of viral persistence [101]. Patients with other forms of agammaglobulinemia or hypogammaglobulinemia are also prone to prolonged virus excretion and VAPP, although the genetic etiologies are often unknown in these patients (Table 1) [104, 106, 117, 119, $121,138]$. Overall, the increased susceptibility to OPV in a small percentage of antibody deficient patients is intriguing. Further studies on these patients, or otherwise healthy individuals who are susceptible to OPV, might help to reveal the genetic and immunological mechanisms underlying polio.

\section{Life-Threatening Infections Caused by the MMR Vaccine}

\section{Measles and the MMR Vaccine}

Measles, mumps, and rubella are three highly contagious viral infections caused by measles virus $(\mathrm{MeV})$, mumps virus $(\mathrm{MuV})$, and rubella virus $(\mathrm{RV})$, respectively. All three viruses are single-stranded RNA (ssRNA) viruses. They cause three clinically and pathologically different types of infection. $\mathrm{MeV}$ causes a self-limited infection characterized by a unique rash, fever, coryza, conjunctivitis, and Koplik's spots in most people. It is transmitted principally by respiratory droplets, and there is an incubation period of about 10 days to the onset of fever and 14 days to the onset of the rash. Complications, such as pneumonia (often secondary bacterial infections) and diarrhea, can occur in up to $40 \%$ of patients. CNS complications, such as autoimmune post-measles encephalomyelitis, can occur in $0.1 \%$ of patients [139]. However, persistent measles infections of the CNS, including measles inclusion body encephalitis and subacute sclerosing panencephalitis (SSPE), are extremely rare (one in 10,000-100,000 patients) [139]. MuV mostly causes painful parotid glands, but the CNS, urinary tract, and genital organs can also be affected. First symptoms may include low-grade fever, anorexia, malaise, and headache [140]. Mumps is transmitted by direct contact, droplet spread, or fomites, with a typical incubation period of 16-18 days.
Sensorineural hearing loss is a well-known complication of mumps. Meningitis arises in 1-10\% of mumps infections, and encephalitis occurs in $0.1 \%$ of patients, with other complications also occasionally observed [140]. RV infection is also mild and self-limited in most individuals, with an average incubation period of 2 weeks. It is characterized by a fine pink rash. Adults, particularly young women, are more likely to develop arthritis, fever, and malaise before the rash appears. Rubella is transmitted via aerosol inhalation or via the blood during pregnancy. Congenital rubella syndrome (CRS) includes various abnormalities, such as ocular, auditory, cardiovascular, and central nervous system defects. The other complications observed include arthritis in young women and systemic infection [141].

The LAVs for measles, mumps, and rubella became available in 1963,1967 , and 1969 , respectively $[1,15,139-142]$. In 1954, Enders and Peebles isolated the measles virus from a child called David Edmonston [15, 143] and used it to establish the foundations for the first measles vaccine [15]. Current $\mathrm{MeV}$ vaccines contain derivatives of the Edmonston or Schwarz virus strain [144]. The mumps vaccine was first licensed in 1967 [140]. The Jeryl Lynn vaccine strain was developed in 1966 from a virus isolated from Maurice Hilleman's daughter, who had developed unilateral parotitis. At least 11 strains of mumps vaccines are currently in use around the world. The Jeryl Lynn and Urabe Am9 strains are the most widely used, followed by the LeningradZagreb, Leningrad-3, and Rubini strains [140]. The rubella virus was first isolated in cell culture in 1962, and the first rubella vaccines were licensed in 1969 and 1970 in the USA and UK [141]. In 1971, a vaccine combining all three viruses, the MMR (measles-mumps-rubella) vaccine, was licensed. The virulent forms of all three viruses are highly contagious, necessitating a very high level of vaccine coverage (most of the population) to establish herd immunity [145]. In regions of high coverage, MMR vaccination has decreased the incidence of each of the diseases targeted by 96 to 99\% [146-148]. However, with the exception of rubella, which was eliminated from the USA in 2015, these three viral infections are still common in many developing countries and occur occasionally in developed countries [149-151].

In rare cases, MMR vaccination may lead to the establishment of severe or chronic infections in children. Severe $\mathrm{MeV}$ vaccine-strain infections are the most frequently reported and best described. Patients may develop measles inclusion-body encephalitis (MIBE) after MMR vaccination [152]. Mortality rates for this condition are as high as $10-20 \%$, with $25 \%$ of survivors experiencing neurological sequelae [152]. MuV vaccine-strain infection is extremely rare [30, 153, 154]. Natural MuV meningitis is benign and associated with a low mortality of mumps encephalitis (about 1.5\%), and long-term morbidity is rare [140]. However, very poor outcomes have been reported for vaccine-related encephalitis [153, 154]. 
Chronic cutaneous granuloma disease associated with RV vaccination in pediatric IEI patients was first recognized in 2014, and about 50 cases have been reported to date [155-160]. Various genetic etiologies have been reported in these patients, including cartilage hair hypoplasia $(\mathrm{CHH})$, ataxia telangiectasia (AT), Simpson-Golabi-Behmel syndrome, Nijmegen breakage syndrome, Marden-Walker syndrome, WHIM syndrome, SCID, CID, including MHC2 and coronin 1A deficiency, CVID, XLA, and NEMO. Many, but not all, of these conditions involve T cell defects. However, $\mathrm{RV}$ vaccine strains were not detected in the granulomas of some patients. Further studies are required to elucidate the pathogenesis of this condition more clearly. Given the rarity of well-defined cases and the lack of mechanistic studies, we will not discuss $\mathrm{MuV}$ and $\mathrm{RV}$ vaccine strains further here and will instead focus on $\mathrm{vMeV}$ infections.

\section{T Cell Deficiencies, from SCID to CID}

Patients with T cell defects, including SCID and CID, have been reported to suffer from disseminated $\mathrm{vMeV}$ infections and MIBE, demonstrating the importance of $\mathrm{T}$ cell function for host defense against vMeV [26, 148, 161-163]. However, such infections are rarely seen in clinical practice, probably because SCID/CIDs are often diagnosed before the first dose of MMR vaccination (Table 1). The report of chronic cutaneous granuloma diseases associated with RV infection in MMR also indicated that these patients, including a variety of SCID and CID, did not develop severe vMeV infections. Among T cell defect, DiGeorge syndrome (DGS) has been well studied in the context of MMR vaccination since the early 2000s [164]. DGS, or chromosome 22q11.2 deletion syndrome and TBX1 deficiency, is a IEI characterized by thymic hypoplasia and small numbers of T cells. Its incidence is 1 in 3000 children [164], and it presents as a wide spectrum of features, including cardiac abnormalities, dysmorphic facial features, and hypocalcemia $[164,165]$. Patients have mild-to-moderate $\mathrm{T}$ cell lymphopenia (affecting the CD4 subset in particular), but intact $T$ cell function [165]. One study characterized a large cohort of DGS patients retrospectively analyzed for adverse events following vaccination [164]. About 23\% (12/52) of MMR vaccine recipients reported mild side effects, including fever, rash, and constitutional symptoms. No severe adverse reactions were reported. In this study, the incidence of vaccine strain infections in DGS patients was similar to that in the general population [164]. Another study suggested that MMR vaccination is also safe in patients with low $\mathrm{CD} 4^{+} \mathrm{T}$ cell counts $\left(<600\right.$ cells $\left./ \mathrm{mm}^{3}\right)$ [165]. A multicenter retrospective cohort study of 194 DGS patients concluded that adverse events occurred after $14 \%$ of MMR vaccine doses, but that most of these events were minor, and no deaths were reported [166].

\section{Inborn Errors of Type I Interferon Immunity}

Deficiencies affecting the innate immune response have recently been shown to be associated with $\mathrm{vMeV}$ infections (Table 1, Fig. 2). Encephalitis after MMR vaccination was reported in a rare case of AR complete STAT1 deficiency, which is usually very severe in patients under the age of 1 year and is a contraindication for subsequent LAV vaccination [167]. Two unrelated kindreds with STAT2 deficiency were reported to suffer from disseminated $\mathrm{vMeV}$ infections and other viral infections [29, 31]. One patient with IRF7 deficiency and another with IRF9 deficiency, both of whom developed severe influenza infections, were reported to develop typical mild $\mathrm{vMeV}$ infections $[168,169]$. An

Fig. 2 Schematic representation of type I and III IFN-related genetic disorders associated with $\mathrm{vMeV}$ infections. In red, genes for which mutations have been associated with $\mathrm{vMeV}$ infections. In black and white, genes not associated with $\mathrm{vMeV}$ infections

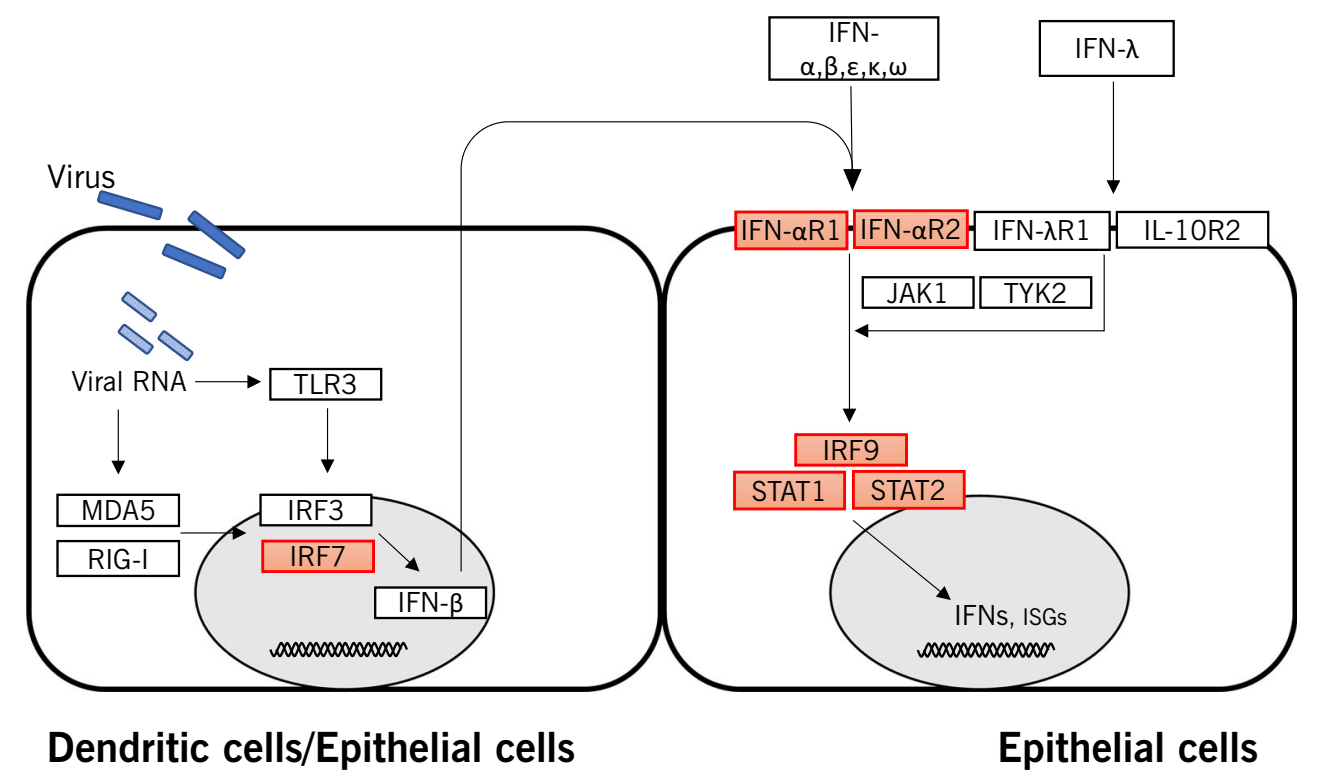


otherwise healthy patient who developed $\mathrm{vMeV}$ infection, and infections with vaccine strains of $\mathrm{MuV}$ and $\mathrm{RV}$, was found to have IFNAR2 deficiency [30]. These cases, although rare, involve type I IFN immunity, and, for IRF7, IRF9, and STAT2, type III IFN immunity, suggesting that type I and III IFN immunity is indispensable for host defense against $\mathrm{vMeV}$. This observation is of considerable interest because wild-type $\mathrm{MeV}$ has been shown to evade the type I IFN response by interfering with the JAK-STAT signaling pathway in natural infections [170]. In wild-type $\mathrm{MeV}$ infections, the virus is introduced into the respiratory tract via an aerosol or respiratory droplets. However, during initial infection, the $\mathrm{P}, \mathrm{V}$, and $\mathrm{C}$ proteins encoded by $\mathrm{MeV}$ can interfere with the type I IFN response by targeting STAT1, STAT2, and IFIH1/MDA5 [170-172], allowing the virus to replicate and spread silently until adaptive immunity is activated. Thus, by the time the typical rash and fever appear in patients, viremia is already well established and the virus has spread throughout the body. Conversely, studies of patients with deficiencies of type I, or type I and III IFN, immunity have clearly shown that infections with vaccine strains of $\mathrm{MeV}$ are controlled by type I and/or III IFNs. Further work is required to identify the genetic etiology of severe infections with wild-type $\mathrm{MeV}$ to resolve this dilemma.

\section{Life-Threatening Infections Caused by Oral Rotavirus Vaccines in SCID Patients}

\section{Rotavirus and ORV}

Rotaviruses cause 114 million episodes of diarrhea, 2.4 million hospital admissions, and 600,000 deaths each year worldwide. By the age of 5 years, nearly all children have been infected [173]. Rotavirus was first isolated from mice and other mammals in the 1960s [174]. In 1973, Bishop and Flewett isolated rotavirus from human for the first time, and it is soon recognized as the most common cause of severe gastroenteritis during childhood [174-176]. It is a double-stranded RNA virus from the Reoviridae family. At least eight different groups (groups $\mathrm{A}-\mathrm{H}$ ) of rotavirus were differentiated on the basis of serological reactivity and genetic variability of viral protein 6 (VP6) [174, 177]. Rotavirus infects mainly the mature enterocytes at the top of the villi of the small intestine in mammalian species, although extra-intestinal spread, including liver, the biliary system, and pancreas, was observed in rare occasions [174]. Typically, the symptoms caused by rotavirus infections are limited in gastrointestinal track, including diarrhea and vomiting, as well as mild fever. Viremia during acute infection has only been recognized recently, and its significance in natural infections remains unclear [178-182]. Rotavirus infections induce the production of IFN $\alpha$, which can be detected in both serum and stools [183, 184]. Currently, two different oral LAVs against rotavirus are being used in most industrialized countries since 2006. RotaTeq, containing the human-bovine pentavalent strains P[8]G1-G4, is used in the US and some European, Latin American, and Asian counties, and Rotatrix, containing the human monovalent strain $\mathrm{P}[8] \mathrm{G} 1$, is used mainly in Latin American and Asian countries [173]. Compared with the human strain Rotatrix, the human-bovine ressortant strains in Rotateq replicate less efficiently in human gut and is shed less frequently in stools; therefore, higher doses and an additional (third) dose is administered [173]. The wide spread use of rotavirus vaccines over the last decade has decreased out patient visits and hospitalization for rotavirus infection by $60-90 \%$ [185].

\section{Life-Threatening ORV Infections in SCID Patients}

Since 2009, 20 SCID patients have been reported to develop severe or chronic infections of the two rotavirus vaccines [19, 20, 186-194], yet no other IEIs have been associated with severe infections due to rotavirus vaccines (Table 1). In these SCID patients, severe diarrhea and vomiting led to life-threatening dehydration in some cases, whereas chronic infections were associated with failure to thrive and prolonged shedding of the virus. Although the vaccines have been shown to be safe for HIV-infected infants in general [195, 196], the SCID cases suggest that they remain unsafe for patients with very low T cell counts. Interestingly, only a few IEI patients, majority having SCID, have been reported to suffer from severe infections of wild-type rotavirus [197-210]. Although chronic diarrhea is a common manifestation in many IEIs, including SCID and antibody deficiencies, wild-type rotavirus does not seem to cause major problem for IEI patients. In large cohorts of SCID and XLA patients who suffered from diarrhea, wild-type virus shedding is sometimes detected, yet usually self-limited and co-infected with other pathogens such as norovirus, enterovirus, and salmonella [208, 209]. The apparent resistance of SCID patients to wild-type rotavirus but not to vaccine strains is intriguing. Several hypotheses potentially explaining this observation should be explored in depth: (1) The earlier exposure to the vaccines, at 2 and 4 months, might contribute to the severity of the gastrointestinal symptoms and susceptibility to dehydration. (2) The severity of the infection might be dose dependent. Indeed, about half of the SCID patients who suffered from infections of the vaccine did not develop severe symptoms until the second or even third dose had been administered, suggesting that an accumulation of viruses in the gut might contribute to the severity of the disease. (3) The vaccine strains may trigger weaker IFN responses than the wild type; therefore, the host defense against the vaccines is dependent exclusively on adaptive immunity $[174,183]$. 


\section{Conclusions}

We have reviewed here severe infections caused by four LAVs: BCG, OPV, vMeV, and ORV. Monogenic inborn errors of immunity have been found to underlie many different infectious diseases in otherwise healthy patients, and the advent of next-generation sequencing (NGS) has facilitated the discovery of new disease-causing genes [211, 212]. A single germline mutation can predispose a patient to a specific infection or to set of related infections. Mutations in different immunity-related pathways cause different phenotypes, and this is also true for LAV infections. IFN- $\gamma$ immunity is crucial for protective immunity to mycobacteria. Patients with inborn errors of this pathway are susceptible to complications of BCG vaccination. Indeed, all known genetic etiologies of MSMD impair IFN- $\gamma$ immunity. For the OPV vaccine, all known genetic etiologies of vaccination complications impair antibody responses to live-attenuated poliovirus. Only a few genetic etiologies of complications of MMR vaccination have been discovered, and they all impair type I IFN immunity. SCID is the only known IEI that is associated with ORVs, highlighting the importance of adaptive immunity in this disease. Several innate immunity pathways have been implicated in LAV infections. The IFN- $\alpha / \beta$, IFN- $\lambda$, and IFN- $\gamma$ pathways may overlap in the generation of responses, and their defects may overlap in complications following LAV vaccination. STAT1 mutations, for example, cause defects of both IFN- $\alpha /$ $\beta$ - and IFN- $\gamma$-mediated responses, leading to possible coinfections with multiple vaccine-derived microbes [167].

In recent years, anti-vaccination groups have, surprisingly, focused on false claims about adverse effects of chemically inactivated or genetically engineered vaccines. They have never highlighted the known adverse effects of LAVs that, tragically but inevitably, harm a very small proportion of vaccinated children. The reason for this is probably that LAVs cause disease for a known reason and in a very small proportion of cases. These anti-vaccination groups deliberately focus on the "unknown," which is perceived as potentially affecting a larger proportion of people and being amenable to neither study nor prevention. Ironically, an ignorance of interindividual variety is also evident in scientific effort to search for non-specific theraputic effects of vaccines, such as BCG in particular, but also MMR and OPV [213]. Such studies have led to earlier and broader use of these LAVs, which will undoubtedly be problematic for many IEI patients. Yet these studies are based on observations of overall decrease in mortality in infants without the identification of a known cause or mechanism [213]. In future studies, the search for new genetic etiologies of adverse effects of BCG, OPV, MMR, and ORV vaccines should not only improve our understanding of adaptive and innate immunity, but should also guide the development of novel, safer vaccines, and new methods for screening children before vaccination with a LAV. The time at which all children undergo exome or genome sequencing at birth is approaching, and this would, in principle, make it possible to identify children with contraindications for LAV vaccination. The same applies to the search for the first genetic etiologies of complications caused by other live vaccines. The main goal in the future will be to search for genetic etiologies of severe or milder disease caused by the LAVs described here and disease caused by other LAVs [153, 154, 214-217]. During the revision of this review, we discovered that autosomal recessive, loss-of-function IFNAR1 deficiencies underlie life-threatening infections of YF vaccine and MMR in otherwise healthy children [218, in press]. This finding is of considerable clinical importance, because families at risk will benefit from genetic counseling to prevent the complications of vaccination with LAVs, and a better understanding of both innate and adaptive immunity involved in the control of LAVs should also improve preventive and therapeutic approaches.

Acknowledgements We thank Dr. Xiaochuan Wang (Children's Hospital of Fudan University, Shanghai), Dr. Luigi D. Notarangelo (National Institute of Allergy and Infectious Diseases, Bethesda), and Dr. Stéphane Blanche (Necker Hospital for Sick Children, Paris) for providing clinical perspectives and extensive discussions. We thank both branches of the Laboratory of Human Genetics of Infectious Diseases for helpful discussions.

Funding This work was supported by the National Institute of Allergy and Infectious Diseases (R37AI095983), the National Vaccine Program Office of the US Department of Health and Human Service (VSRNV000006), the St. Giles Foundation, the Rockefeller University, Institute National de la Santé et de la Recherche Médicale (INSERM), Paris Descartes University, the Integrative Biology of Emerging Infectious Diseases Laboratory of Excellence (ANR-10-LABX-62-IBEID), and the French National Research Agency under the "Investments for the future" program (grant number ANR-10-IAHU-01), ANR-GENMSMD (ANR-16-CE17-0005-01 for JB), SRC2017 (for JB), and ECOS-NORD (C19S01-63407 for JB).

\section{Compliance with Ethical Standards}

Conflict of Interest The authors declare that they have no conflict of interest.

\section{References}

1. Minor PD. Live attenuated vaccines: historical successes and current challenges. Virology. 2015;479-480:379-92.

2. Gans HA. The status of live viral vaccination in early life. Vaccine. 2013;31(21):2531-7.

3. Bonilla FA. Update: vaccines in primary immunodeficiency. $\mathbf{J}$ Allergy Clin Immunol. 2018;141(2):474-81.

4. Sobh A, Bonilla FA. Vaccination in primary immunodeficiency disorders. J Allergy Clin Immunol Pract. 2016;4(6):1066-75.

5. Plotkin S. History of vaccination. Proc Natl Acad Sci U S A. 2014;111(34):12283-7.

6. Luca S, Mihaescu T. History of BCG vaccine. Maedica (Buchar). 2013;8(1):53-8.

7. Lam LKM, et al. Gamma-interferon exerts a critical early restriction on replication and dissemination of yellow fever virus vaccine strain 17D-204. NPJ Vaccines. 2018;3:5. 
8. de Menezes Martins R, Fernandes Leal Mda L, Homma A. Serious adverse events associated with yellow fever vaccine. Hum Vaccin Immunother. 2015;11(9):2183-7.

9. Norrby E. Yellow fever and Max Theiler: the only Nobel prize for a virus vaccine. J Exp Med. 2007;204(12):2779-84.

10. Frierson JG. The yellow fever vaccine: a history. Yale J Biol Med. 2010;83(2):77-85.

11. Driss N, Ben-Mustapha I, Mellouli F, Ben Yahia A, Touzi H, Bejaoui $\mathrm{M}$, et al. High susceptibility for enterovirus infection and virus excretion features in Tunisian patients with primary immunodeficiencies. Clin Vaccine Immunol. 2012;19(10):1684 9.

12. Baicus A. History of polio vaccination. World J Virol. 2012;1(4): 108-14.

13. Katz SL, Enders JF, Holloway A. Studies on an attenuated measles-virus vaccine. II. Clinical, virologic and immunologic effects of vaccine in institutionalized children. N Engl J Med. 1960;263:159-61.

14. Stokes J Jr, et al. Use of living attenuated measles-virus vaccine in early infancy. N Engl J Med. 1960;263:230-3.

15. Katz SL, Enders JF, Holloway A. The development and evaluation of an attenuated measles virus vaccine. Am J Public Health Nations Health. 1962;52(2)Suppl):5-10.

16. Casanova JL, et al. Immunological conditions of children with BCG disseminated infection. Lancet. 1995;346(8974):581.

17. Macdonald HN, van Rooyen CE. Clinical surveillance after feeding oral attenuated live polio vaccine. Can Med Assoc J. 1963;88(20):1017-9.

18. Pestri T. Encephalitis after live measles virus vaccine. Can Med Assoc J. 1966;94(21):1133.

19. Werther RL, et al. Rotavirus vaccine induced diarrhea in a child with severe combined immune deficiency. J Allergy Clin Immunol. 2009;124(3):600.

20. Bakare N, et al. Severe combined immunodeficiency (SCID) and rotavirus vaccination: reports to the Vaccine Adverse Events Reporting System (VAERS). Vaccine. 2010;28(40):6609-12.

21. Ramon Guerra AU, et al. Congenital familial hypogammaglobulinemia with familial severe generalized moniliasis \& atypical reactions following BCG vaccination. Rev Colomb Pediatr Pueric. 1957;16(Spec No):102-15.

22. Ramon-Guerra AU, Queirolo CA, Temesio N. Syndrome of severe infectious complication of BCG, extensive moniliasis \& familial hypogammaglobulinemia. Arch Pediatr Urug. 1958;29(9): 618-32.

23. Bodechtel $\mathrm{G}$, et al. Gesundheitsschäden nach oraler Impfung mit dem Poliomyelitis-Impfstoff Typ I von Sabin. Dtsch Med Wochenschr. 1963;88(38):1821-8.

24. JOPPICK G. Paralytic diseases following oral vaccination with Sabin type I. Sympos Europ Assoc Polio. 1963;9:170-2.

25. Wyatt HV. Poliomyelitis in hypogammaglobulinemics. J Infect Dis. 1973;128(6):802-6.

26. Mawhinney $\mathrm{H}$, et al. Dysgammaglobulinaemia complicated by disseminated measles. Br Med J. 1971;2(5758):380-1.

27. Boisson-Dupuis S, et al. Inborn errors of human STAT1: allelic heterogeneity governs the diversity of immunological and infectious phenotypes. Curr Opin Immunol. 2012;24(4):364-78.

28. Bustamante $\mathrm{J}$, et al. Mendelian susceptibility to mycobacterial disease: genetic, immunological, and clinical features of inborn errors of IFN-gamma immunity. Semin Immunol. 2014;26(6): 454-70.

29. Hambleton S, et al. STAT2 deficiency and susceptibility to viral illness in humans. Proc Natl Acad Sci U S A. 2013;110(8):30538.

30. Duncan CJ, et al. Human IFNAR2 deficiency: lessons for antiviral immunity. Sci Transl Med. 2015;7(307):307ra154.
31. Moens L, et al. A novel kindred with inherited STAT2 deficiency and severe viral illness. J Allergy Clin Immunol. 2017;139(6): 1995-1997 e9.

32. Zwerling A, Behr MA, Verma A, Brewer TF, Menzies D, Pai M. The BCG World Atlas: a database of global BCG vaccination policies and practices. PLoS Med. 2011;8(3):e1001012.

33. Ying W, et al. Clinical characteristics and immunogenetics of BCGosis/BCGitis in Chinese children: a 6 year follow-up study. PLoS One. 2014;9(4):e94485.

34. Zufferey C, Germano S, Dutta B, Ritz N, Curtis N. The contribution of non-conventional $\mathrm{T}$ cells and NK cells in the mycobacterial-specific IFNgamma response in Bacille CalmetteGuerin (BCG)-immunized infants. PLoS One. 2013;8(10): e77334.

35. Sadeghi-Shabestari M, Rezaei N. Disseminated bacille CalmetteGuerin in Iranian children with severe combined immunodeficiency. Int J Infect Dis. 2009;13(6):e420-3.

36. Bernatowska EA, et al. Disseminated bacillus Calmette-Guerin infection and immunodeficiency. Emerg Infect Dis. 2007;13(5): 799-801.

37. Marciano BE, Huang CY, Joshi G, Rezaei N, Carvalho BC, Allwood Z, et al. BCG vaccination in patients with severe combined immunodeficiency: complications, risks, and vaccination policies. J Allergy Clin Immunol. 2014;133(4):1134-41.

38. Lotte A, et al. Second IUATLD study on complications induced by intradermal BCG-vaccination. Bull Int Union Tuberc Lung Dis. 1988;63(2):47-59.

39. Hesseling AC, Johnson LF, Jaspan H, Cotton MF, Whitelaw A, Schaaf HS, et al. Disseminated bacille Calmette-Guerin disease in HIV-infected south African infants. Bull World Health Organ. 2009;87(7):505-11.

40. Casanova JL, Abel L. Genetic dissection of immunity to mycobacteria: the human model. Annu Rev Immunol. 2002;20: 581-620.

41. Bolursaz MR, Lotfian F, Velayati AA. Bacillus Calmette-Guerin vaccine complications in Iranian children at a university hospital. Allergol Immunopathol (Madr). 2017;45(4):356-61.

42. Norouzi S, et al. Bacillus Calmette-Guerin (BCG) complications associated with primary immunodeficiency diseases. J Inf Secur. 2012;64(6):543-54.

43. O'Brien KL, et al. Bacillus Calmette-Guerin complications in children born to HIV-1-infected women with a review of the literature. Pediatrics. 1995;95(3):414-8.

44. Boisson-Dupuis $\mathrm{S}$, et al. Inherited and acquired immunodeficiencies underlying tuberculosis in childhood. Immunol Rev. 2015;264(1):103-20.

45. Rosain J, et al. Mendelian susceptibility to mycobacterial disease: 2014-2018 update. Immunol Cell Biol. 2019;97(4):360-7.

46. Canessa $\mathrm{C}$, et al. Bcgitis and vaccine-derived poliovirus infection in a patient with a novel deletion in RAG1 binding site. Int $\mathrm{J}$ Immunopathol Pharmacol. 2013;26(2):511-5.

47. Fischer A, et al. Severe combined immunodeficiencies and related disorders. Nat Rev Dis Primers. 2015;1:15061.

48. Heiman $\mathrm{S}$, et al. Co-appearance of OPV and BCG vaccine-derived complications in two infants with severe combined immunodeficiency. Immunol Res. 2018;66(3):437-43.

49. Roxo-Junior $\mathrm{P}$, et al. A family history of serious complications due to $\mathrm{BCG}$ vaccination is a tool for the early diagnosis of severe primary immunodeficiency. Ital J Pediatr. 2013;39:54.

50. Mazzucchelli JT, et al. Severe combined immunodeficiency in Brazil: management, prognosis, and BCG-associated complications. J Investig Allergol Clin Immunol. 2014;24(3):184-91.

51. Bukhari E, et al. Disseminated bacille Calmette-Guerin disease in Saudi children: clinical profile, microbiology, immunology evaluation and outcome. Eur Rev Med Pharmacol Sci. 2016;20(17): 3696-702. 
52. Trimble R, Atkins J, Quigg TC, Burns CC, Wallace GS, Thomas $\mathrm{M}$, et al. Vaccine-associated paralytic poliomyelitis and BCG-osis in an immigrant child with severe combined immunodeficiency syndrome-Texas, 2013. MMWR Morb Mortal Wkly Rep. 2014;63(33):721-4.

53. Al-Herz W, Al-Mousa H. Combined immunodeficiency: the Middle East experience. J Allergy Clin Immunol. 2013;131(3):658-60.

54. Picard C, et al. International Union of Immunological Societies: 2017 primary immunodeficiency diseases committee report on inborn errors of immunity. J Clin Immunol. 2018;38(1):96-128.

55. Assari T. Chronic granulomatous disease; fundamental stages in our understanding of CGD. Med Immunol. 2006;5:4.

56. Leiding JW, Holland SM. Chronic Granulomatous Disease. 2012 Aug 9 [Updated 2016 Feb 11]. In: Adam MP, Ardinger HH, Pagon RA, et al., editors. GeneReviews ${ }^{\circledR}$ [Internet]. Seattle (WA): University of Washington, Seattle; 1993-2019. Available from: https://www.ncbi.nlm.nih.gov/books/NBK99496/.

57. Parvaneh N, et al. Visceral leishmaniasis in two patients with IL12 p40 and IL-12R $\beta 1$ deficiencies. Pediatr Blood Cancer. 2017;64:e26362. https://doi.org/10.1002/pbc.26362.

58. Lee WI, et al. Immune defects in active mycobacterial diseases in patients with primary immunodeficiency diseases (PIDs). J Formos Med Assoc. 2011;110(12):750-8.

59. Tajik $\mathrm{S}$, et al. A novel CYBB mutation in chronic granulomatous disease in Iran. Iran J Allergy Asthma Immunol. 2016;15(5):426-9.

60. Conti $\mathrm{F}$, et al. Mycobacterial disease in patients with chronic granulomatous disease: a retrospective analysis of 71 cases. J Allergy Clin Immunol. 2016;138(1):241-248.e3.

61. Martel C, et al. Clinical, functional and genetic analysis of twentyfour patients with chronic granulomatous disease-identification of eight novel mutations in CYBB and NCF2 genes. J Clin Immunol. 2012;32(5):942-58.

62. Di Matteo G, et al. Molecular characterization of a large cohort of patients with chronic granulomatous disease and identification of novel CYBB mutations: an Italian multicenter study. Mol Immunol. 2009;46(10):1935-41.

63. Arnadottir GA, et al. A homozygous loss-of-function mutation leading to $\mathrm{CYBC} 1$ deficiency causes chronic granulomatous disease. Nat Commun. 2018;9(1):4447.

64. Thomas DC, et al. EROS/CYBC1 mutations: decreased NADPH oxidase function and chronic granulomatous disease. J Allergy Clin Immunol. 2019;143(2):782-785 e1.

65. Averbuch D, et al. The clinical spectrum of patients with deficiency of signal transducer and activator of transcription-1. Pediatr Infect Dis J. 2011;30(4):352-5.

66. Bustamante J, et al. BCG-osis and tuberculosis in a child with chronic granulomatous disease. J Allergy Clin Immunol. 2007;120(1):32-8.

67. Deffert C, Cachat J, Krause KH. Phagocyte NADPH oxidase, chronic granulomatous disease and mycobacterial infections. Cell Microbiol. 2014;16(8):1168-78.

68. Baba LA, Ailal F, el Hafidi N, Hubeau M, Jabot-Hanin F, Benajiba $\mathrm{N}$, et al. Chronic granulomatous disease in Morocco: genetic, immunological, and clinical features of 12 patients from 10 kindreds. J Clin Immunol. 2014;34(4):452-8.

69. de Oliveira-Junior EB, Zurro NB, Prando C, Cabral-Marques O, Pereira PVS, Schimke LF, et al. Clinical and genotypic spectrum of chronic granulomatous disease in 71 Latin American patients: first report from the LASID registry. Pediatr Blood Cancer. 2015;62(12):2101-7.

70. El Hawary R, et al. Role of flow cytometry in the diagnosis of chronic granulomatous disease: the Egyptian experience. J Clin Immunol. 2016;36(6):610-8.

71. Zhou Q, et al. A cohort of 169 chronic granulomatous disease patients exposed to BCG vaccination: a retrospective study from a single center in Shanghai, China (2004-2017). J Clin Immunol. 2018;38(3):260-72.
72. van den Berg JM, et al. Chronic granulomatous disease: the European experience. PLoS One. 2009;4(4):e5234.

73. Bustamante J, et al. Germline CYBB mutations that selectively affect macrophages in kindreds with $\mathrm{X}$-linked predisposition to tuberculous mycobacterial disease. Nat Immunol. 2011;12(3): 213-21.

74. Ramirez-Alejo N, Santos-Argumedo L. Innate defects of the IL$12 /$ IFN-gamma axis in susceptibility to infections by mycobacteria and salmonella. J Interf Cytokine Res. 2014;34(5): 307-17.

75. Alcais A, et al. Tuberculosis in children and adults: two distinct genetic diseases. J Exp Med. 2005;202(12):1617-21.

76. Kreins AY, et al. Human TYK2 deficiency: mycobacterial and viral infections without hyper-IgE syndrome. J Exp Med. 2015;212(10):1641-62.

77. Kong XF, et al. Disruption of an antimycobacterial circuit between dendritic and helper T cells in human SPPL2a deficiency. Nat Immunol. 2018;19(9):973-85.

78. Martinez-Barricarte R, et al. Human IFN-gamma immunity to mycobacteria is governed by both IL-12 and IL-23. Sci Immunol. 2018;3(30).

79. Casanova JL, Abel L. Human genetics of infectious diseases: unique insights into immunological redundancy. Semin Immunol. 2018;36:1-12.

80. Kong XF, et al. A novel form of cell type-specific partial IFNgammaR1 deficiency caused by a germ line mutation of the IFNGR1 initiation codon. Hum Mol Genet. 2010;19(3):434- 44.

81. Oleaga-Quintas C, et al. A purely quantitative form of partial recessive IFN-gammaR2 deficiency caused by mutations of the initiation or second codon. Hum Mol Genet. 2019;28(3):524.

82. Casanova JL, Holland SM, Notarangelo LD. Inborn errors of human JAKs and STATs. Immunity. 2012;36(4):515-28.

83. Dorman SE, et al. Clinical features of dominant and recessive interferon gamma receptor 1 deficiencies. Lancet. 2004;364(9451):2113-21.

84. Khanolkar A, et al. CD4 T cell-restricted IL-2 signaling defect in a patient with a novel IFNGR1 deficiency. J Allergy Clin Immunol. 2018;141(1):435-439 e7.

85. Aytekin C, et al. Bacille Calmette-Guerin lymphadenitis and recurrent oral candidiasis in an infant with a new mutation leading to interleukin-12 receptor beta-1 deficiency. J Investig Allergol Clin Immunol. 2011;21(5):401-4.

86. Hambleton S, et al. IRF8 mutations and human dendritic-cell immunodeficiency. N Engl J Med. 2011;365(2):127-38.

87. Filipe-Santos $\mathrm{O}$, et al. X-linked susceptibility to mycobacteria is caused by mutations in NEMO impairing CD40-dependent IL-12 production. J Exp Med. 2006;203(7):1745-59.

88. Okada S, et al. IMMUNODEFICIENCIES. Impairment of immunity to Candida and Mycobacterium in humans with bi-allelic RORC mutations. Science. 2015;349(6248):606-13.

89. Boisson-Dupuis S, et al. Tuberculosis and impaired IL-23dependent IFN-gamma immunity in humans homozygous for a common TYK2 missense variant. Sci Immunol. 2018;3(30). https://doi.org/10.1126/sciimmunol.aau8714.

90. Nieuwenhuizen NE, Kaufmann SHE. Next-generation vaccines based on Bacille Calmette-Guerin. Front Immunol. 2018;9:121.

91. Schrager LK, Harris RC, Vekemans J. Research and development of new tuberculosis vaccines: a review. F1000Res. 2018;7:1732.

92. Tullius MV, et al. A replication-limited recombinant Mycobacterium bovis BCG vaccine against tuberculosis designed for human immunodeficiency virus-positive persons is safer and more efficacious than BCG. Infect Immun. 2008;76(11):5200-14.

93. Grode L, et al. Increased vaccine efficacy against tuberculosis of recombinant Mycobacterium bovis bacille Calmette-Guerin mutants that secrete listeriolysin. J Clin Invest. 2005;115(9):2472-9. 
94. Groschel MI, et al. ESX secretion systems: mycobacterial evolution to counter host immunity. Nat Rev Microbiol. 2016;14(11): 677-91.

95. Sun R, et al. Novel recombinant $\mathrm{BCG}$ expressing perfringolysin $\mathrm{O}$ and the over-expression of key immunodominant antigens; preclinical characterization, safety and protection against challenge with Mycobacterium tuberculosis. Vaccine. 2009;27(33):441223.

96. Gengenbacher M, et al. Dietary pyridoxine controls efficacy of vitamin B6-auxotrophic tuberculosis vaccine bacillus CalmetteGuerin DeltaureC::hly Deltapdx1 in mice. MBio. 2014;5(3): e01262-14.

97. Velmurugan $\mathrm{K}$, et al. Mycobacterium tuberculosis nuoG is a virulence gene that inhibits apoptosis of infected host cells. PLoS Pathog. 2007;3(7):e110.

98. Eggers HJ. Milestones in early poliomyelitis research (1840 to 1949). J Virol. 1999;73(6):4533-5.

99. Sabin AB, Ward R. the natural history of human poliomyelitis : I. Distribution of virus in nervous and non-nervous tissues. J Exp Med. 1941;73(6):771-93.

100. Sabin AB. Pathogenesis of poliomyelitis; reappraisal in the light of new data. Science. 1956;123(3209):1151-7.

101. Nathanson N. The pathogenesis of poliomyelitis: what we don't know. Adv Virus Res. 2008;71:1-50.

102. De Jesus NH. Epidemics to eradication: the modern history of poliomyelitis. Virol J. 2007;4:70.

103. Nathanson N, Martin JR. The epidemiology of poliomyelitis: enigmas surrounding its appearance, epidemicity, and disappearance. Am J Epidemiol. 1979;110(6):672-92.

104. Li L, et al. Poliovirus excretion among persons with primary immune deficiency disorders: summary of a seven-country study series. J Infect Dis. 2014;210(Suppl 1):S368-72

105. Platt LR, Estivariz CF, Sutter RW. Vaccine-associated paralytic poliomyelitis: a review of the epidemiology and estimation of the global burden. J Infect Dis. 2014;210(Suppl 1):S380-9.

106. Shaghaghi M, et al. New insights into physiopathology of immunodeficiency-associated vaccine-derived poliovirus infection; systematic review of over 5 decades of data. Vaccine. 2018;36(13):1711-9.

107. Zaffran $\mathrm{M}$, et al. The polio endgame: securing a world free of all polioviruses. Lancet. 2018;391(10115):11-3.

108. Morales M, Tangermann RH, Wassilak SG. Progress toward polio eradication - worldwide, 2015-2016. MMWR Morb Mortal Wkly Rep. 2016;65(18):470-3

109. Minor P. Vaccine-derived poliovirus (VDPV): impact on poliomyelitis eradication. Vaccine. 2009;27(20):2649-52

110. Burns CC, et al. Vaccine-derived polioviruses. J Infect Dis. 2014;210(Suppl 1):S283-93.

111. Bandyopadhyay AS, Modlin JF, Wenger J, Gast C. Immunogenicity of new primary immunization schedules with inactivated poliovirus vaccine and bivalent oral polio vaccine for the polio endgame: a review. Clin Infect Dis. 2018;67(suppl_1):S35-41.

112. WHO. Vaccine-associated paralytic polio (VAPP) and vaccinederived poliovirus (VDPV) 2015 [cited 2019 May 14th ]; Available from: https://www.who.int/immunization/diseases/ poliomyelitis/endgame objective2/oral polio vaccine/ VAPPandcVDPVFactSheet-Feb2015.pdf?ua=1

113. Melnick JL. Advantages and disadvantages of killed and live poliomyelitis vaccines. Bull World Health Organ. 1978;56(1):21-38.

114. Shahmahmoodi $S$, et al. Vaccine-associated paralytic poliomyelitis in immunodeficient children, Iran, 1995-2008. Emerg Infect Dis. 2010;16(7):1133-6.

115. Nkowane BM, et al. Vaccine-associated paralytic poliomyelitis. United States: 1973 through 1984. JAMA. 1987;257(10):133540.
116. Shaghaghi M, Parvaneh N, Ostad-Rahimi P, Fathi SM, Shahmahmoodi S, Abolhassani H, et al. Combined immunodeficiency presenting with vaccine-associated paralytic poliomyelitis: a case report and narrative review of literature. Immunol Investig. 2014;43(3):292-8.

117. Macklin G, et al. Prolonged excretion of poliovirus among individuals with primary immunodeficiency disorder: an analysis of the World Health Organization registry. Front Immunol. 2017;8: 1103.

118. Aghamohammadi A, et al. Patients with primary immunodeficiencies are a reservoir of poliovirus and a risk to polio eradication. Front Immunol. 2017;8:685.

119. de Silva R, Gunasena S, Ratnayake D, Wickremesinghe GD, Kumarasiri CD, Pushpakumara BAW, et al. Prevalence of prolonged and chronic poliovirus excretion among persons with primary immune deficiency disorders in Sri Lanka. Vaccine. 2012;30(52):7561-5.

120. Sazzad HM, et al. The feasibility of identifying children with primary immunodeficiency disorders: preparation for the polio post-eradication era in Bangladesh. Vaccine. 2012;30(36):5396400.

121. Sazzad HM, et al. Screening for long-term poliovirus excretion among children with primary immunodeficiency disorders: preparation for the polio posteradication era in Bangladesh. J Infect Dis. 2014;210(Suppl 1):S373-9.

122. Foiadelli $\mathrm{T}$, et al. Nucleotide variation in Sabin type 3 poliovirus from an Albanian infant with agammaglobulinemia and vaccine associated poliomyelitis. BMC Infect Dis. 2016;16:277.

123. Aluri J, et al. Clinical, immunological, and molecular findings in five patients with major histocompatibility complex class II deficiency from India. Front Immunol. 2018;9:188.

124. Parvaneh N, et al. Vaccine-associated paralytic poliomyelitis in a patient with MHC class II deficiency. J Clin Virol. 2007;39(2): $145-8$.

125. El Hawary RE, et al. MHC-II Deficiency Among Egyptians: Novel Mutations and Unique Phenotypes. J Allergy Clin Immunol Pract. 2019;7(3):856-63.

126. Schubert A, Bottcher S, Eis-Hubinger AM. Two cases of vaccinederived poliovirus infection in an oncology ward. N Engl J Med. 2016;374(13):1296-8.

127. Driss N, et al. Sequential asymptomatic enterovirus infections in a patient with major histocompatibility complex class II primary immunodeficiency. J Clin Microbiol. 2014;52(9):3486-9.

128. Lopez C, et al. Nonparalytic poliovirus infections in patients with severe combined immunodeficiency disease. J Pediatr. 1974;84(4):497-502.

129. Asturias EJ, et al. Poliovirus excretion in Guatemalan adults and children with HIV infection and children with cancer. Biologicals. 2006;34(2):109-12.

130. Moss WJ, Clements CJ, Halsey NA. Immunization of children at risk of infection with human immunodeficiency virus. Bull World Health Organ. 2003;81(1):61-70.

131. Notarangelo LD. Primary immunodeficiencies. J Allergy Clin Immunol. 2010;125(2 Suppl 2):S182-94.

132. Sabin AB. Commentary on report on oral poliomyelitis vaccines. JAMA. 1964;190:52-5.

133. Shaghaghi $\mathrm{M}$, et al. Clearing vaccine-derived poliovirus infection following hematopoietic stem cell transplantation: a case report and review of literature. J Clin Immunol. 2018;38(5):610-6.

134. Plebani A, et al. Clinical, immunological, and molecular analysis in a large cohort of patients with X-linked agammaglobulinemia: an Italian multicenter study. Clin Immunol. 2002;104(3):221-30.

135. Chen XF, et al. Clinical characteristics and genetic profiles of 174 patients with X-linked agammaglobulinemia: report from Shanghai, China (2000-2015). Medicine (Baltimore). 2016;95(32):e4544. 
136. Guo J, et al. Immunodeficiency-related vaccine-derived poliovirus (iVDPV) cases: a systematic review and implications for polio eradication. Vaccine. 2015;33(10):1235-42.

137. Fiore L, et al. Search for poliovirus long-term excretors among patients affected by agammaglobulinemia. Clin Immunol. 2004;111(1):98-102.

138. Shaghaghi M, et al. Vaccine-derived polioviruses and children with primary immunodeficiency, Iran, 1995-2014. Emerg Infect Dis. 2016;22(10):1712-9.

139. Moss WJ, Griffin DE. Measles. Lancet. 2012;379(9811):153-64.

140. Hviid A, Rubin S, Muhlemann K. Mumps. Lancet. 2008;371(9616):932-44.

141. Banatvala JE, Brown DW. Rubella. Lancet. 2004;363(9415): 1127-37.

142. Griffin DE. Measles Vaccine. Viral Immunol. 2018;31(2):86-95.

143. Enders JF, Peebles TC. Propagation in tissue cultures of cytopathogenic agents from patients with measles. Proc Soc Exp Biol Med. 1954;86(2):277-86.

144. Kowalzik F, Faber J, and Knuf M. MMR and MMRV vaccines. Vaccine. 2018;36(36):5402-7.

145. Measles vaccines. WHO position paper-April 2017. Wkly Epidemiol Rec. 2017;92(17):205-27.

146. Peltola H, et al. Measles, mumps, and rubella in Finland: 25 years of a nationwide elimination programme. Lancet Infect Dis. 2008;8(12):796-803.

147. Bottiger M, et al. Swedish experience of two dose vaccination programme aiming at eliminating measles, mumps, and rubella. Br Med J (Clin Res Ed). 1987;295(6608):1264-7.

148. Lievano F, et al. Measles, mumps, and rubella virus vaccine (MM-RII): a review of 32 years of clinical and postmarketing experience. Vaccine. 2012;30(48):6918-26.

149. WHO. Mumps: Immunization, Vaccines and Biologicals. 2016 [cited 2019 May 14th]; Available from: https://www.who.int/ immunization/diseases/mumps/en/.

150. WHO. Measles: Immunization, Vaccines and Biologicals. 2018 [cited 2019 May 14th]; Available from: https://www.who.int/ immunization/diseases/measles/en/.

151. WHO. Rubella. 2019 [cited 2019 May 14th]; Available from: https://www.who.int/news-room/fact-sheets/detail/rubella.

152. Makela A, Nuorti JP, Peltola H. Neurologic disorders after measles-mumps-rubella vaccination. Pediatrics. 2002;110(5): 957-63.

153. Mumps meningitis and MMR vaccination. Lancet. 1989;2(8670): 1015-6.

154. Morfopoulou S, Mee ET, Connaughton SM, Brown JR, Gilmour $\mathrm{K}$, Chong WK' $\mathrm{K}$ ', et al. Deep sequencing reveals persistence of cell-associated mumps vaccine virus in chronic encephalitis. Acta Neuropathol. 2017;133(1):139-47.

155. Bayer DK, et al. Vaccine-associated varicella and rubella infections in severe combined immunodeficiency with isolated CD4 lymphocytopenia and mutations in IL7R detected by tandem whole exome sequencing and chromosomal microarray. Clin Exp Immunol. 2014;178(3):459-69.

156. Neven B, et al. Cutaneous and visceral chronic granulomatous disease triggered by a rubella virus vaccine strain in children with primary immunodeficiencies. Clin Infect Dis. 2017;64(1):83-6.

157. Bodemer $\mathrm{C}$, et al. Live rubella virus vaccine long-term persistence as an antigenic trigger of cutaneous granulomas in patients with primary immunodeficiency. Clin Microbiol Infect. 2014;20(10): O656-63.

158. Perelygina L, et al. Rubella persistence in epidermal keratinocytes and granuloma M2 macrophages in patients with primary immunodeficiencies. J Allergy Clin Immunol. 2016;138(5):1436-1439 e11.

159. Buchbinder D. et al. Rubella virus-associated cutaneous granulomatous disease: a unique complication in immune-deficient patients, not limited to DNA repair disorders. J Clin Immunol. 2019;39(1):81-9.

160. Perelygina L, et al. Outcomes for nitazoxanide treatment in a case series of patients with primary immunodeficiencies and Rubella Virus-Associated Granuloma. J Clin Immunol. 2019;39(1):112-7.

161. Mihatsch MJ, et al. Lethal measles giant cell pneumonia after live measles vaccination in a case of thymic alymphoplasia Gitlin. Helv Paediatr Acta. 1972;27(2):143-6.

162. Monafo WJ, et al. Disseminated measles infection after vaccination in a child with a congenital immunodeficiency. J Pediatr. 1994;124(2):273-6.

163. Bitnun A, et al. Measles inclusion-body encephalitis caused by the vaccine strain of measles virus. Clin Infect Dis. 1999;29(4):85561.

164. Perez EE, Bokszczanin A, McDonald-McGinn D, Zackai EH, Sullivan KE. Safety of live viral vaccines in patients with chromosome 22q11.2 deletion syndrome (DiGeorge syndrome/ velocardiofacial syndrome). Pediatrics. 2003;112(4):e325.

165. Azzari C, et al. Safety and immunogenicity of measles-mumpsrubella vaccine in children with congenital immunodeficiency (DiGeorge syndrome). Vaccine. 2005;23(14):1668-71.

166. Hofstetter AM, et al. Live vaccine use and safety in DiGeorge syndrome. Pediatrics. 2014;133(4):e946-54.

167. Burns $\mathrm{C}$, et al. A novel presentation of homozygous loss-offunction STAT-1 mutation in an infant with hyperinflammation - a case report and review of the literature. $\mathrm{J}$ Allergy Clin Immunol Pract. 2016;4(4):777-9.

168. Ciancanelli MJ, et al. Infectious disease. Life-threatening influenza and impaired interferon amplification in human IRF7 deficiency. Science. 2015;348(6233):448-53.

169. Hernandez N, et al. Life-threatening influenza pneumonitis in a child with inherited IRF9 deficiency. J Exp Med. 2018;215(10): 2567-2585.

170. Ramachandran A, Parisien JP, Horvath CM. STAT2 is a primary target for measles virus $\mathrm{V}$ protein-mediated alpha/beta interferon signaling inhibition. J Virol. 2008;82(17):8330-8.

171. Devaux P, et al. A recombinant measles virus unable to antagonize STAT1 function cannot control inflammation and is attenuated in rhesus monkeys. J Virol. 2011;85(1):348-56.

172. Audsley MD, Moseley GW. Paramyxovirus evasion of innate immunity: diverse strategies for common targets. World J Virol. 2013;2(2):57-70.

173. Grimwood K, Buttery JP. Clinical update: rotavirus gastroenteritis and its prevention. Lancet. 2007;370(9584):302-4.

174. Desselberger U. Rotaviruses. Virus Res. 2014;190:75-96.

175. Bishop RF, et al. Virus particles in epithelial cells of duodenal mucosa from children with acute non-bacterial gastroenteritis. Lancet. 1973;2(7841):1281-3.

176. Flewett TH, Bryden AS, Davies H. Letter: virus particles in gastroenteritis. Lancet. 1973;2(7844):1497.

177. Crawford SE, et al. Rotavirus infection. Nat Rev Dis Primers. 2017;3:17083.

178. Blutt SE, Conner ME. Rotavirus: to the gut and beyond! Curr Opin Gastroenterol. 2007;23(1):39-43.

179. Blutt SE, et al. Rotavirus antigenemia in children is associated with viremia. PLoS Med. 2007;4(4):e121.

180. Candy DC. Rotavirus infection: a systemic illness? PLoS Med. 2007;4(4):e117.

181. Hemming M, et al. Rotavirus antigenemia in children is associated with more severe clinical manifestations of acute gastroenteritis. Pediatr Infect Dis J. 2014;33(4):366-71.

182. Blutt SE, et al. Rotavirus antigenaemia and viraemia: a common event? Lancet. 2003;362(9394):1445-9.

183. Arnold MM, Patton JT. Rotavirus antagonism of the innate immune response. Viruses. 2009;1(3):1035-56. 
184. Angel J, Franco MA, Greenberg HB. Rotavirus immune responses and correlates of protection. Curr Opin Virol. 2012;2(4):419-25.

185. de Hoog MLA, et al. Report of the 5th European expert meeting on rotavirus vaccination (EEROVAC). Hum Vaccin Immunother. 2018;14(4):1027-34.

186. Centers for Disease, C. and Prevention. Addition of severe combined immunodeficiency as a contraindication for administration of rotavirus vaccine. MMWR Morb Mortal Wkly Rep. 2010;59(22):687-8.

187. Patel NC, et al. Vaccine-acquired rotavirus in infants with severe combined immunodeficiency. N Engl J Med. 2010;362(4):314-9.

188. Uygungil B, et al. Persistent rotavirus vaccine shedding in a new case of severe combined immunodeficiency: a reason to screen. $\mathrm{J}$ Allergy Clin Immunol. 2010;125(1):270-1.

189. Patel NC, et al. Chronic rotavirus infection in an infant with severe combined immunodeficiency: successful treatment by hematopoietic stem cell transplantation. Clin Immunol. 2012;142(3):399-401.

190. Kaplon J, Cros G, Ambert-Balay K, Leruez-Ville M, Chomton M, Fremy $\mathrm{C}$, et al. Rotavirus vaccine virus shedding, viremia and clearance in infants with severe combined immune deficiency. Pediatr Infect Dis J. 2015;34(3):326-8.

191. Morillo-Gutierrez B, Worth A, Valappil M, Gaspar HB, Gennery AR. Chronic infection with rotavirus vaccine strains in UK children with severe combined immunodeficiency. Pediatr Infect Dis J. 2015;34(9):1040-1.

192. Bogaert D, et al. Persistent rotavirus diarrhea post-transplant in a novel JAK3-SCID patient after vaccination. Pediatr Allergy Immunol. 2016;27(1):93-6.

193. Rosenfeld L, et al. Life-threatening systemic rotavirus infection after vaccination in severe combined immunodeficiency (SCID). Pediatr Allergy Immunol. 2017;28(8):841-3.

194. Yoshikawa T, et al. Persistent systemic rotavirus vaccine infection in a child with X-linked severe combined immunodeficiency. J Med Virol. 2019;91(6):1008-13.

195. Laserson KF, et al. Safety of the pentavalent rotavirus vaccine (PRV), RotaTeq((R)), in Kenya, including among HIV-infected and HIV-exposed infants. Vaccine. 2012;30(Suppl 1):A61-70.

196. Levin MJ, et al. Safety and immunogenicity of a live attenuated pentavalent rotavirus vaccine in HIV-exposed infants with or without HIV infection in Africa. AIDS. 2017;31(1):49-59.

197. Saulsbury FT, Winkelstein JA, Yolken RH. Chronic rotavirus infection in immunodeficiency. J Pediatr. 1980;97(1):61-5.

198. Booth IW, et al. Protracted diarrhoea, immunodeficiency and viruses. Eur J Pediatr. 1982;138(3):271-2.

199. Chrystie IL, et al. Multiple faecal virus excretion in immunodeficiency. Lancet. 1982;1(8266):282.

200. Pedley S, et al. The genomes of rotaviruses isolated from chronically infected immunodeficient children. J Gen Virol. 1984;65(Pt 7):1141-50.

201. Eiden J, et al. Rotavirus RNA variation during chronic infection of immunocompromised children. Pediatr Infect Dis. 1985;4(6):632-7.

202. Wood DJ, David TJ, Chrystie IL, Totterdell B. Chronic enteric virus infection in two T-cell immunodeficient children. J Med Virol. 1988;24(4):435-44.
203. Oishi I, et al. Serial observations of chronic rotavirus infection in an immunodeficient child. Microbiol Immunol. 1991;35(11):95361.

204. Gilger MA, et al. Extraintestinal rotavirus infections in children with immunodeficiency. J Pediatr. 1992;120(6):912-7.

205. Richardson S, Grimwood K, Gorrell R, Palombo E, Barnes G, Bishop R. Extended excretion of rotavirus after severe diarrhoea in young children. Lancet. 1998;351(9119):1844-8.

206. Conley ME, Howard V. Clinical findings leading to the diagnosis of X-linked agammaglobulinemia. J Pediatr. 2002;141(4):566-71.

207. Nakano I, et al. Sudden death from systemic rotavirus infection and detection of nonstructural rotavirus proteins. J Clin Microbiol. 2011;49(12):4382-5.

208. van de Ven AA, et al. The role of prolonged viral gastrointestinal infections in the development of immunodeficiency-related enteropathy. Clin Rev Allergy Immunol. 2012;42(1):79-91.

209. Nanishi E, et al. A nationwide survey of common viral infections in childhood among patients with primary immunodeficiency diseases. J Inf Secur. 2016;73(4):358-68.

210. Parvaneh L, et al. Infectious etiology of chronic diarrhea in patients with primary immunodeficiency diseases. Eur Ann Allergy Clin Immunol. 2019;51(1):32-7.

211. Casanova JL. Severe infectious diseases of childhood as monogenic inborn errors of immunity. Proc Natl Acad Sci U S A. 2015;112(51):E7128-37.

212. Casanova JL. Human genetic basis of interindividual variability in the course of infection. Proc Natl Acad Sci U S A. 2015;112(51): E7118-27.

213. de Bree LCJ, et al. Non-specific effects of vaccines: current evidence and potential implications. Semin Immunol. 2018;39:3543.

214. Reinhardt B, et al. Development of viremia and humoral and cellular parameters of immune activation after vaccination with yellow fever virus strain 17D: a model of human flavivirus infection. J Med Virol. 1998;56(2):159-67.

215. Pulendran B, et al. Case of yellow fever vaccine-associated viscerotropic disease with prolonged viremia, robust adaptive immune responses, and polymorphisms in CCR5 and RANTES genes. J Infect Dis. 2008;198(4):500-7.

216. Silva ML, et al. Clinical and immunological insights on severe, adverse neurotropic and viscerotropic disease following 17D yellow fever vaccination. Clin Vaccine Immunol. 2010;17(1):118 26.

217. Seligman SJ, et al. Defining risk groups to yellow fever vaccineassociated viscerotropic disease in the absence of denominator data. Am J Trop Med Hyg. 2014;90(2):267-71.

218. Hernandez N, et al. Inherited IFNAR1 deficiency in otherwise healthy patients with adverse reaction to measles and yellow fever live vaccines. J Exp Med. 2019 (in press).

Publisher's Note Springer Nature remains neutral with regard to jurisdictional claims in published maps and institutional affiliations. 